\title{
Fisiología y valor diagnóstico del moco cervical
}

\author{
POR EL DOCTOR FRANCISCO PARDo VARgas
}

Del Departamento de Ginecología del Hospital de San José.

El moco cervical es un elemento secretorio, elaborado por las glándulas del endocérvix, que fluye por el orificio cervical de manera constante. En las diferentes etapas de la vida de la mujer y condicionado por las influencias hormonales consecutivas, el moco cervical presenta, dentro de lo normal, variaciones que se refieren tanto a su composición química como a sus caracteres físicos; por esta razón el estudio de ellas debe hacerse teniendo en cuenta la etapa genital correspondiente.

\section{PROPIEDADES FISICO-QUIMICAS}

\section{1.-Cantidad}

En la recién nacida, debido al influjo hormonal materno, el epitelio endocervical muestra una intensa actividad proliferativa y secretora que desaparece al cesar dicho influjo, y por consiguiente es de muy corta duración.

En la niñez el moco cervical es prácticamente nulo y aumenta solamente al acercarse la menarquia.

En las menopáusicas ya estables, amenorreicas secundarias graves y castradas quirúrgicas o por irradiación, el cuello se encuentra en reposo y su secreción es escasa o nula.

En las embarazadas hay aumento de mucina y modificaciones intensas del epitelio de revestimiento, estroma y tejido glandular, llegando a simular verdaderos procesos neoplásicos.

En el ciclo menstrual la cantidad varía según el momento: así, en los días correspondientes al post-menstruo y hasta el noveno día, hay alrededor de 60 miligramos de secreción diaria, cantidad que aumenta en forma rápida durante cuatro días y en el momento de la ovulación se aprecian 200 a 700 miligra- 
mos; de este momento en adelante decrece bruscamente y la cantidad hallada en el premenstruo es prácticamente exigua.

2.-Contenido en gua, materias secas y cloruro de sodio

El agua contenida en el moco sufre un paralelo al de la secreción y así de 92 a $94 \%$ en el post-menstruo, se eleva para liegar a su máximo que es de $97 \%$ en el intermenstruo y decrecer posteriormente hasta alcanzar las cifras iniciales.

Landerstron-Lang practicó el estudio de la secreción cervical, identificando cristales de cloruro de sodio y mucina. El análisis por microtitulación ofreció los siguientes resultados:

Cantidad total de secreción ... .. . $\quad 365.3$ mgmos.

$\begin{array}{lllllllllll}\text { Materias secas . . . . . . . . . . . . . } & \ldots & 5.9 & \text { " } & 1.62 \%\end{array}$

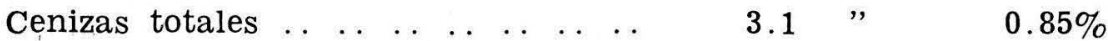

Materias orgánicas . . . . . . . . . $\quad 2.8 \% ", \quad 0.77 \%$

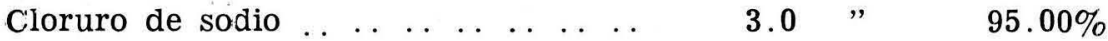

de la ceniza total.

\section{3.- Contenido hidrocarbonado}

Los principales componentes hidrocarbonados del moco cervical son el glucógeno, la glucosa y la maltosa, y el máximo porcentaje respectivo con relación al ciclo se halla, para el glucógeno, en el octavo día; para la maltosa en el décimo y para la glucosa en el décimosexto día. Hasta el momento no se ha demostrado la presencia de fructuosa, y el total de sustancias reductoras asciende a 97 mgmos. por ciento en la fase ovulatoria y las sustancias reductoras libres tienen menor poder reductor al aproximarse el 140 día del ciclo.

4. - P. H.

La reacción de la secreción cervical ha sido estudiada por numerosos investigadores, pero aún no se ha dicho la última palabra al respecto. Sin embargo, la mayoría de los autores están de acuerdo en concluir que dicha reacción es francamente alcalina y parece evidente la tendencia hacia la acidez en las mujeres estériles.

\section{5.-Presión osmótica}

La presión osmótica durante la ovulación corresponde a la de la solución normal y es mayor en las otras fases del ciclo. 
Esta observación tiene gran importancia desde el punto de vista de la influencia que el cambio de presión osmótica ejerce sobre la motilidad del espermatozoide.

\section{6. - Actividad de la fosfatasa alcalina}

Los depósitos de fosfatasa alcalina sufren variaciones cíciicas y su presencia en mayor cantidad guarda relación directa con la actividad estrogénica y proliferación del epitelio.

\section{7.-Contenido bacteriano}

Después de las reglas el moco cervical contiene saprofitos banales en muy escasa cantidad: aumentan en la fase de ovulación y alcanzan su máximo en la fase luteínica. Es de anotar que el mencionado aumento no guarda paralelismo con la cantidad de leucocitos. En el moco extraído del exocérvix, Fulconis halló la mayor cantidad al final del ciclo en un 35.7\%; en el intermenstruo la encontró en el $19.3 \%$ y al final de la menstruación en el $5.77 \%$, siendo flora banal. Basado en estos resultados, el autor admite la posibilidad de ellos como índice para determinar la ovulación.

\section{8.-Propiedades cualitativas}

Se refieren al aspecto, viscosidad, elasticidad y cristalización.

a) Aspecto.- El aspecto del moco cervical varía del limpio cristalino al opaco o "sucio"; estas variaciones se encuentran intimamente relacionadas con el nivel estrogénico, siendo más limpio cuanta mayor sea la cantidad de estrógenos. Clift, estuciando la transparencia del contenido cervical, dice que normalmente el moco posee una zona central ligeramente turbia que separa dos zonas laterales completamente transparentes, hecho que ocurre fuera del intermenstruo, ya que durante éste las tres zonas son totalmente límpidas.

b) Elasticidad.- El moco cervical es generalmente elástico. Esta propiedad, sin embargo, tiene variaciones normales dentro del ciclo menstrual; así, entre mayor sea la influencia estrogénica tanto más elástica se aprecia la secreción, y mientras menos elástica sea, menor será la cantidad de estrógenos. Clift mide en centímetros el hilo que se forma al separar una gota de moco ubicada en un portaobjeto; esta propiedad de formar filamentos es mayor en el momento de la ovulación. La constancia de esta característica hizo que Clift la propusiera como test de ovulación. 
c) Viscosidad.- Tanto en la fase folicular como en la luteínica, aunque un poco más durante la última, el moco es viscoso; esta viscosidad disminuye en el intermenstruo para, de esta manera, dejar de ser un obstáculo mecánico tanto en la entrada como en la progresión del elemento fecundante.

d) Cristalización.- Bajo el influjo de las hormonas ováricas el moco cervical tiene la propiedad de cristalizarse en formas diversas pero precisas cuya observación es índice muy seguro para juzgar el estado de los ciclos ováricos y endometrial. Creemos que el mecanismo de tal fenómeno se base en la acción del estrógeno que actuaría modificando la constitución del moco, en el sentido de producir dentro de él una concentración determinada de cloruro de sodio, óptima para provocar la cristalización típica. Y esta concentración se produciria por influencia directa del estrógeno sobre las glándulas del epitelio endocervical que modificarían su secreción en tal sentido.

\section{CASUISTICA}

Se presentan las experiencias realizadas "in vitro" y en 100 mujeres en diferentes épocas de la vida y en diversos estados endocrinos, tanto normales como patológicos, agrupándolas en la siguiente forma:

El primer grupo está constituído por 30 casos, 15 de los cuales corresponden a mujeres climatéricas y los 15 restantes a mujeres normales en la segunda mitad del ciclo menstrual, comprobado por medio de la citología vaginal y la biopsia de endometrio.

El segundo grupo comprende 20 casos de ciclo normal bifásico, estudiados en diferentes fases del mismo y comprobados por medio de citología vaginal y de biopsia endometrial.

El tercer grupo consiste en 10 pacientes climatéricas controladas antes y después de las experiencias.

El cuarto lo constituyen 33 casos de embarazo comprendidos entre la quinta semana y el octavo mes.

El quinto comprende 6 casos, agrupados en la siguiente forma:

a) Cuatro casos de ciclo monofásico comprobados por medio de estudios seriados de la citología vaginal y de la biopsia de endometrio;

b) Un caso de aborto inminente;

c) Un caso estudiado a los quince días de haber presentado un aborto molar, y 
d) Un caso de corioepitelioma.

Para la obtención del moco cervical se emplea un espéculo vaginal común y una pinza acodada de curaciones. Una vez introducido el espéculo sin lubricante alguno, por temor a alterar la composición del moco, se procede a la toma de la muestra: solo cuando hay secreciones muy abundantes o patológicas agregadas, se limpia el orificio cervical externo. La pinza es introducida suavemente dentro del orificio cervical, en una profundidad de medio centímetro; se entreabren ligeramente sus ramas y luego se cierran para aprisionar una pequeña cantidad de moco entre ellas. Teniendo cuidado de no ir a provocar traumatismos en el cuello, pues la hemorragia consiguiente alteraría los resultados, se retira la pinza y una vez afuera se abren las ramas con delicadeza y se observan las características de la secreción; en seguida se extiende sobre una lámina porta objetos y se deja secar espontáneamente o por medio del calor: esto nos parece indiferente. Una vez seco se observa el extendido al microscopio y se juzga el fenómeno de la cristalización.

Resultado del estudio de las caracteristicas del moco cervical

Primer grupc.- Experiencias "in vitro" y con 30 mujeres (15 climatéricas y 15 en fase secretora). Para probar que el cloruro de sodio cristaliza en presencia de la mucina, se empleó la albúmina de huevo, proteína semejante a aquélla, cuya imagen microscópica es la de una red de tela de araña (Fig. 1).

Al mezclarse cloruro de sodio hasta proporciones mínimas del $0.5 \%$ se obtiene la cristalización típica en hoja de helecho (Fig. 2) .

A las muestras obtenidas en las pacientes climatéricas y en aquellas que se encontraban en la segunda mitad del ciclo, en las cuales no se presentaba la cristalización típica por déficit estrogénico y por acción inhibidora de la progesterona, respectivamente, se agregó una gota de cloruro de sodio en las mismas concentraciones empleadas en la prueba realizada "in vitro" (de $0.9 \%$ a $0.5 \%$ ) y el resultado fue el mismo, es decir, la cristalización en hoja de helecho apareció en las preparaciones (Fig. 3)

Segundo grupo.- 20 ciclos ovulatorios:

10 En el cuarto día se observó moco escaso, adherente, viscoso y poco elástico, y la cristalización se hizo en forma de cristales libres de forma tetraédrica; existen en el extendido células de descamación vaginal y algunos leucocitos (Fig. 4). 


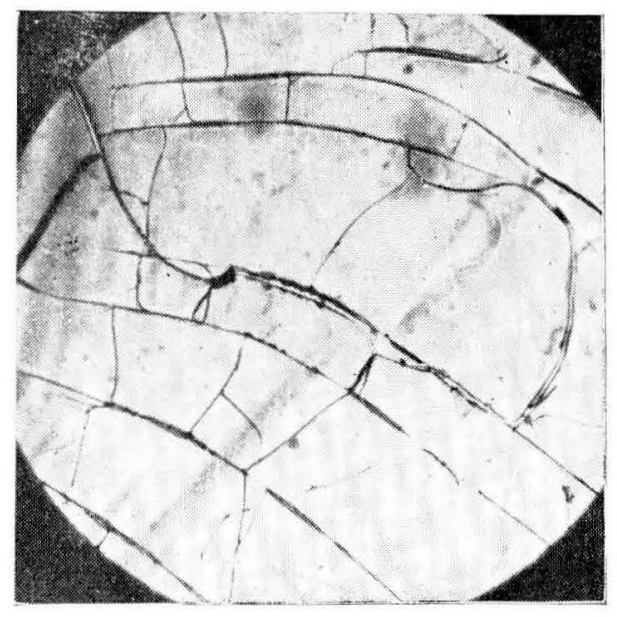

Figura 1.

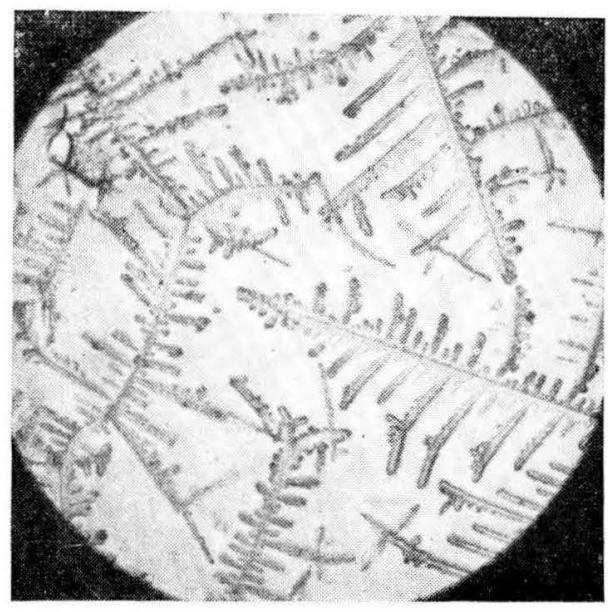

Figura 2.

20 Hacia el sexto día la secreción se ha vuelto más abundante, su aspecto se clarifica notablemente, aumenta su elasticidad y se torna mucho más fluída. Los cristales tetraédricos libres tienden a confluir y se esbozan ya las arborizaciones en forma de hojas de helecho. Las células descamativas y leucocitarias disminuyen en número dando al extendido un aspecto más limpio (Fig. 5). 


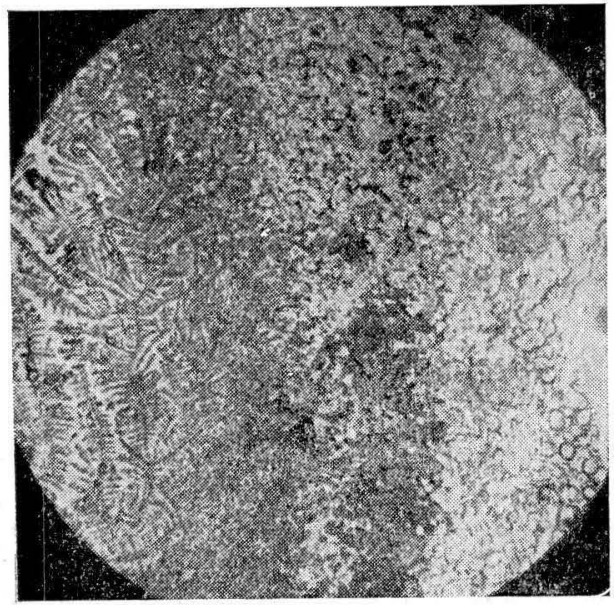

FIgURA 3

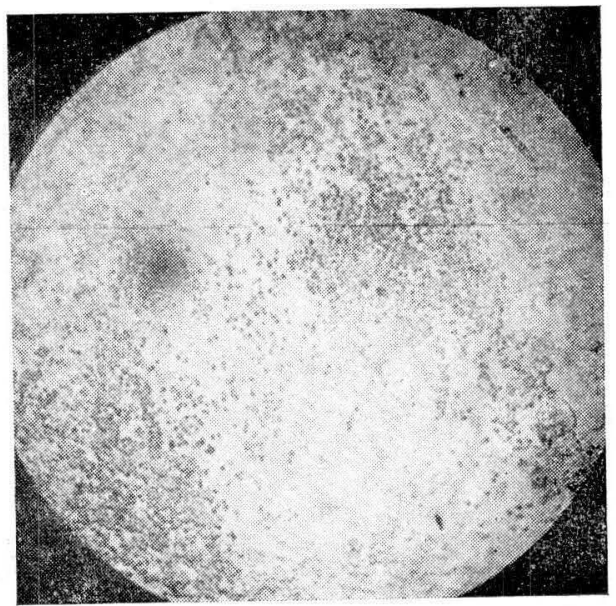

FIgURA 4

En el décimosexto día el moco es mucho más abundante, su aspecto es francamente cristalino, límpido y su elasticidad es muy apreciable. La cristalización ha progresado y las arborizaciones se han desarrollado y sistematizado, alcanzando en esta época un gran parecido a las hojas de helecho ("Fernlike"), que se va acentuando y alcanza su máximo entre éste y el 170 día (Fig. 6).

49 Durante el tiempo transcurrido entre el 179 y el 23 9 dia, se observa poca disminución de la cantidad de moco, su aspecto 


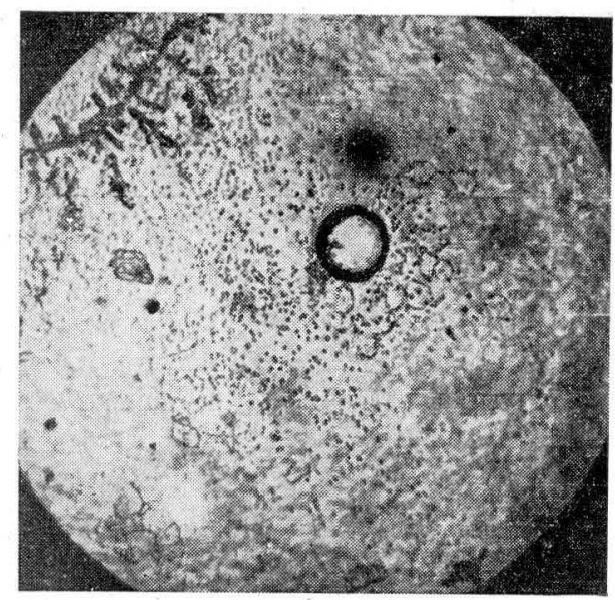

FIGURA 5

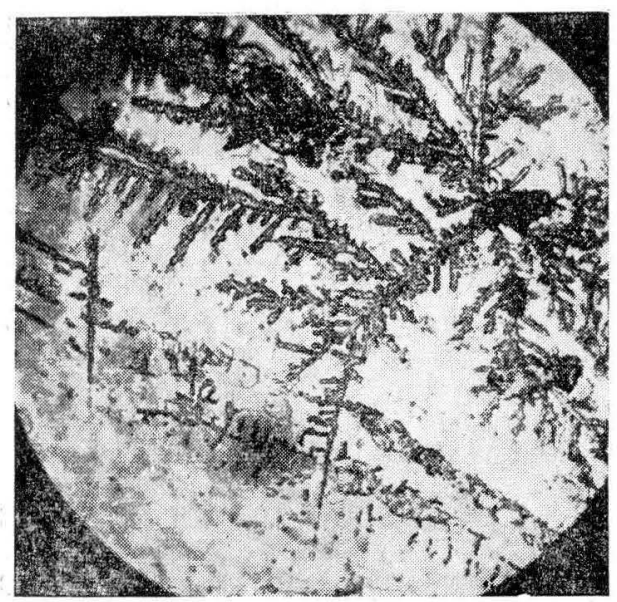

Figura 6

continúa igualmente límpido, y su elasticidad persiste de manera apreciable. En cuanto a la cristalización, no es de ninguna manera excepcional que durante este tiempo persistan las formaciones típicas de hoja de helecho (Fig. 7).

50 En las tomas practicadas el 270 día se encuentra moco escaso, viscoso, adherente y poco elástico; las imágenes de hoja de helecho han desaparecido y en su lugar se observan manchas o placas de moco de límites imprecisos y de formas caprichosas. 


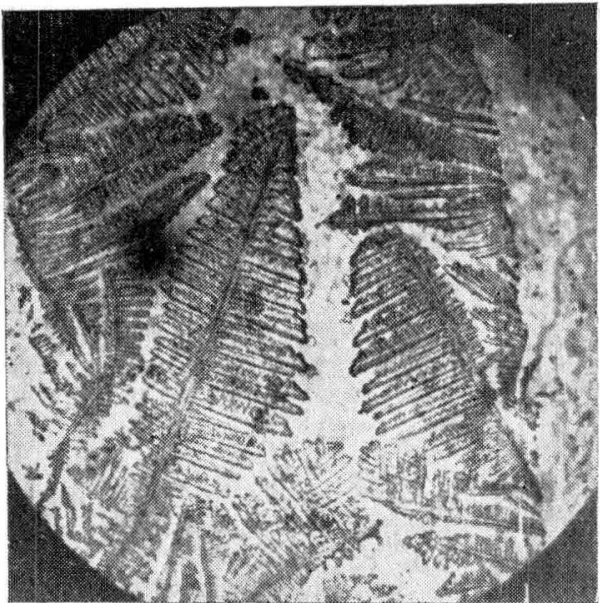

FIgURA 7

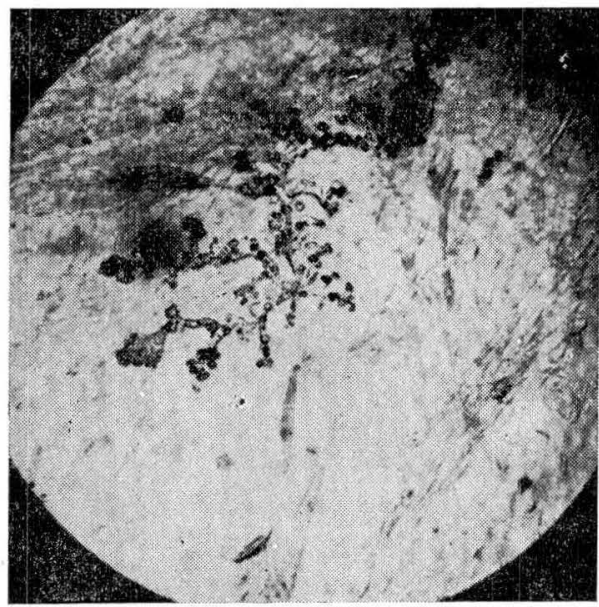

Figura 8

no siendo raro descubrir cristales libres semejantes a los encontrados en los primeros días del ciclo (Fig. 8).

Tercer grupo._- Diez mujeres climatéricas. La secreción en general es escasa, viscosa y no se aprecian zonas de cristalización. Al cabo de ocho días de ser sometidas a la administración diaria de 0.010 mgmos. de Etinil-estradiol, puede apreciarse un aumento en la cantidad, transparencia y fluidez de la secreción, así como 


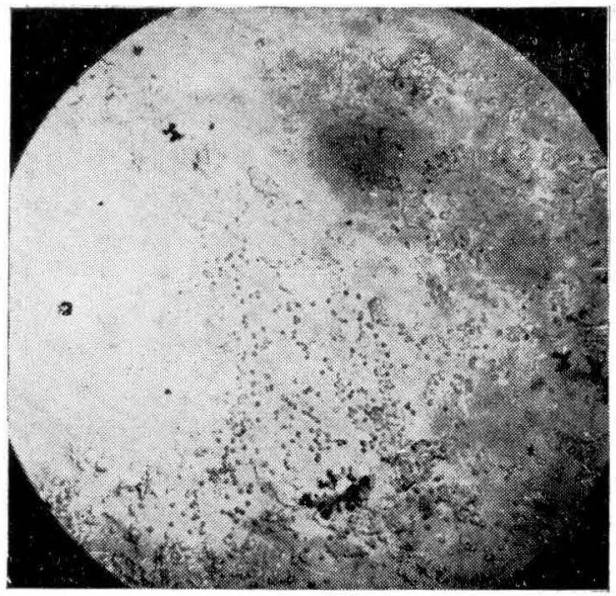

Figura 9 A

Moco cervical antes de la administración de estrógenos

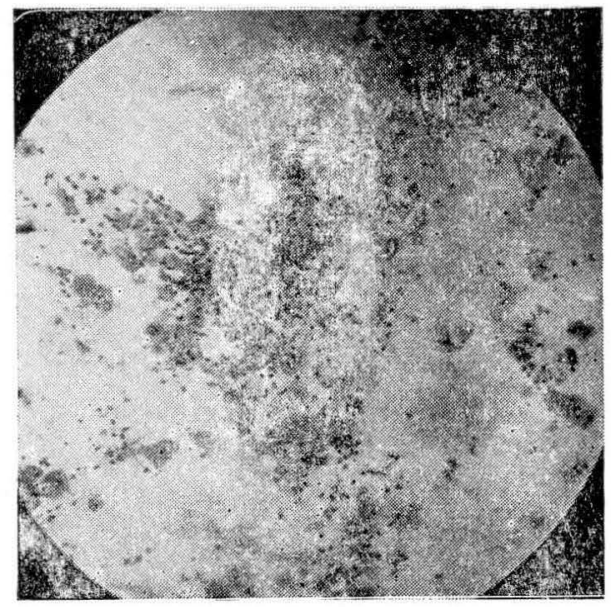

FIgURA 9 B

Citología vaginal correspondiente a la misma paciente en igual época.

también la presencia de zonas de cristalización típica en hoja de helecho (Figs. 9 y 10)| 


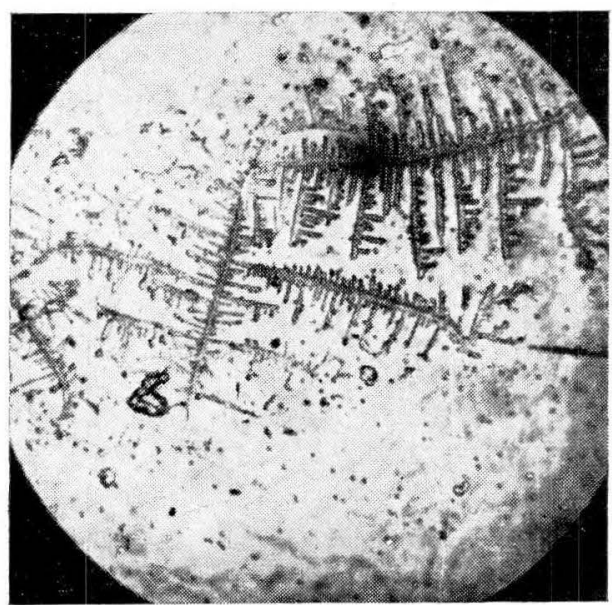

FIGURA $10 \mathrm{~A}$

Control del moco cervical en la misma paciente después de la adim nistración de estrógenos.

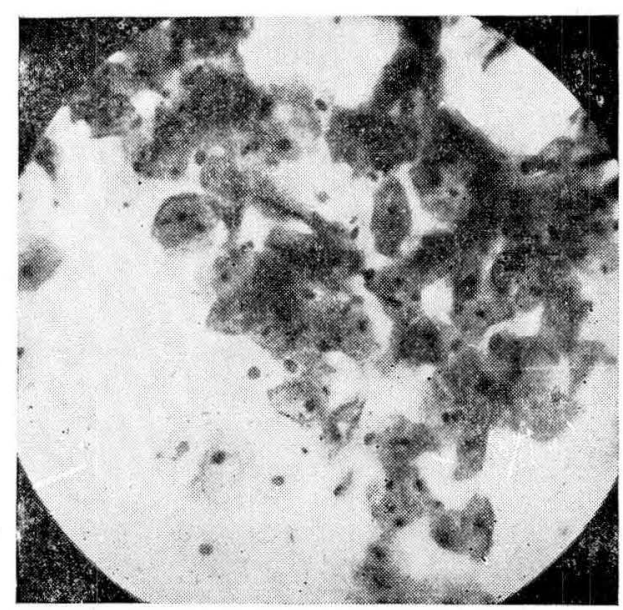

FIgura $10 \mathrm{~B}$

Citología vaginal correspondiente a la figura $10 \mathrm{~A}$.

Cuarto grupo. - Treinta y tres casos de embarazo.

10 En ningún caso de embarazo comprendido entre la quinta y la décima semana se observó cristalización (Fig. 11). 


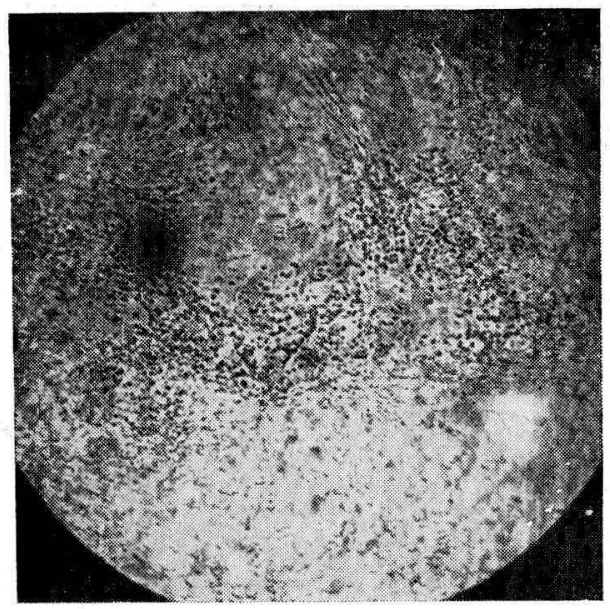

Figura 11

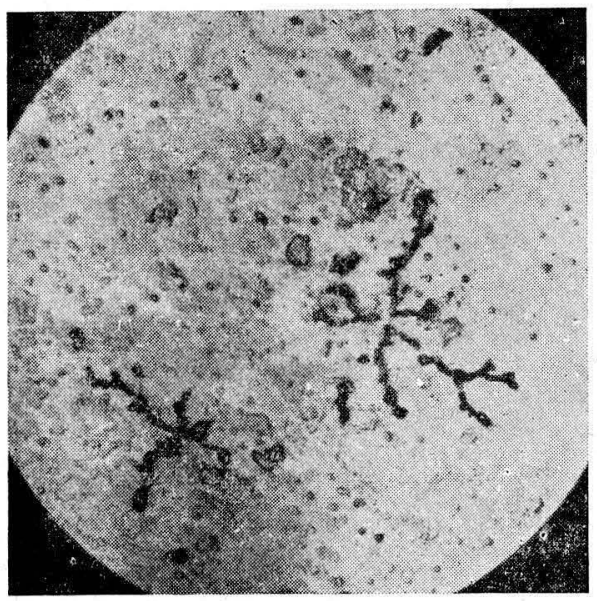

Figura 12

20 La cristalización en arborizaciones en forma de roseta es más frecuente entre el tercero y el quinto mes del embarazo (Fig. 12).

30 En ningún embarazo mayor de 5 meses se observó la cristlización en roseta o en hoja de helecho.

4 ị En relación con el aspecto y la cantidad del moco, se observó que al llegar la gestación a su cuarto mes, la secreción endocervical tiende a volverse transparente y más fluida, dato que 
seguramente refleja una situación determinada por la actividad placentaria, pues es un hecho aceptado que a partir de tal época la secreción de la hormona gonadotropa coriónica disminuye considerablemente y en cambio aparece la producción de la foliculina por la placenta.

Quinto grupo.- Casos varios.

1 ํ. En cuatro casos de cíclo monofásico de tipo prolongado se presentó de manera constante la imagen típica en hoja de helecho (Figis. 13 A y 13 B).

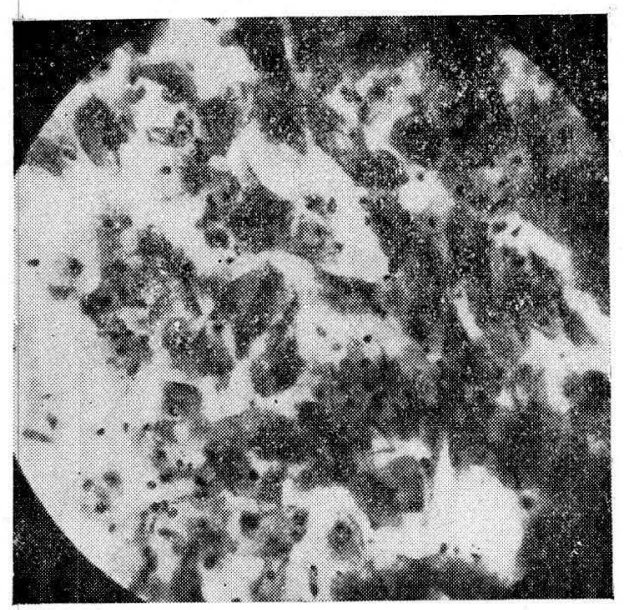

Figura 13 A

Moco cervical en un caso de ciclo monofásico.

2 o Un caso de aborto inminente, estudiado pocas horas antes de consumarse, demostró un moco escaso, viscoso, adherente y con cristalización negativa.

30 En un caso de Mola Hidatiforme y en ctro de Corioepitelioma, se obtuvo un moco con todas las características del moco "progesterónico" esto es, cantidad regular o escasa, aspecto turbio, elasticidad disminuída y cristalización negativa. 


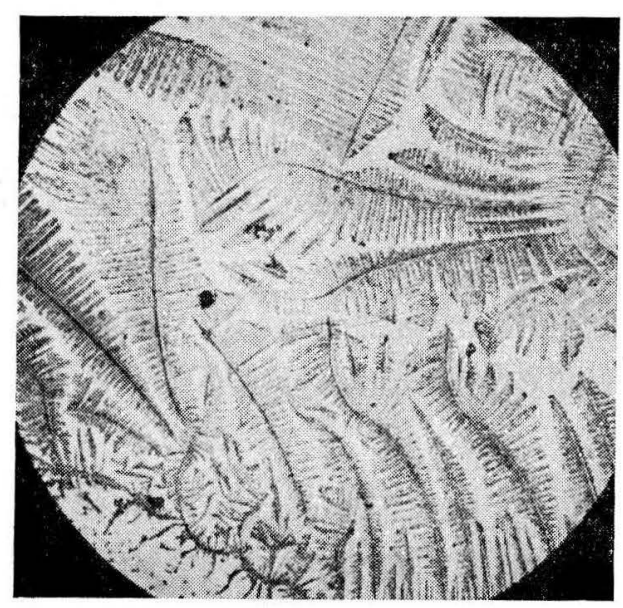

FIgURA 13 B

Citología vaginal correspondiente.

\section{COMENTARIOS}

19 El estudio del moco cervical constituye un valioso recurso en el diagnóstico funcional ginecológico.

$2^{\circ}$ La sencillez y simplicidad de su técnica hacen que el método pueda ser empleado en la misma consulta, obteniendo así un importante elemento de juicio que servirá de guía, tanto para el diagnóstico como para la terapéutica.

3o El estudio comparado del moco cervical con la citología vaginal y la biopsia de endometrio, demostró una concordancia absoluta en todos los casos.

40 Aunque consideramos el fenómeno de la cristalización como el más importante para fines diagnósticos, creemos que la observación de las otras características propias del moco cervical, como son el aspecto, la cantidad, la fluidez y la elasticidad, constituyen también elementos de juicio que en ningún caso se deben subestimar. Sostenemos por lo mismo, que el estudio de la secreción no estará completo si se ha omitido alguna de estas propiedades.

50 Las modificaciones que experimenta la secreción endocervical están conducidas a la concentración de las hormonas ováricas, y se traducen por un moco limpio, elástico, abundante, 
fluído, de cristalización positiva en caso de predominio estrogénico, o por moco opaco, no extensible, escaso, de cristalización negativa cuando hay déficit foliculínico o influencia de la progesterona.

60 Es evidente que el elemento que, cristaliza es el cloruro de sodio.

7o Para que se produzca la cristalización típica es preciso que el cloruro de sodio se encuentre en una concentración determinada. Por ello creemos que el estrógeno actúa modificando la constitución del moco en el sentido de producir dentro de él una concentración determinada de cloruro de sodio óptima para provocar la cristalización típica. Y esta concentración se produciría por la influencia directa del estrógeno sobre las glándulas del epitelio endocervical, que modificaría su secreción en tal sentido. En forma similar, aunque de manera contraria, actuaría la progesterona.

80 En todo estudio de moco cervical deben tenerse presentes las causas de error; éstas se refieren a los elementos que alteran el medio, ya sea en sus propiedades químicas o en sus caracteres físicos. Tal sucede con las secreciones agregadas o patológicas que producen variaciones del P. H., en el contenido acuoso, en la concentración de cloruro de sodio, en la presencia de leucocitos, etc. De manera que los elementos secretorios o hemáticos producidos por cervicitis latentes o purulentas, por cuellos erosionados y sangrantes, por pólipos hemorrágicos o por simples maniobras algo bruscas, se mezclan al moco extraído para impedir o nublar la cristalización, formando un concepto falso acerca de lo que se busca.

90 El empleo de otros recursos diagnósticos como la colpocitología y la biopsia endometrial sirven de complemento feliz a todo estudio funcional y por ello debe procurarse aprovechar la misma sesión para obtener las muestras correspondientes. El estudio del moco cervical tiene la ventaja de su respuesta inmediata y segura, que puede proporcionarnos normas de conducta muy aceptables en tanto nos lleguen los otros datos, los cuales. según los resultados obtenidos en nuestras experiencias, han confirmado siempre los proporcionados por la secreción endocervical.

Nota.- El anterior estudio es el resumen del trabajo titulado Contribución al estudio de la secreción endocervical utérina. T'esis de grado. Universidad Javeriana. 1954. (Edit. Cooperativa de Artes Gráficas), Bogotá, cuya bibliografía es la siguiente: 


\section{BIBLIOGRAFIA}

1. CURTIS ARThuR H.- "Ginecología”. I. Ed. Española. 1941. Págs. 42 1952.

2. CONILL-MONTOBBIO, VICTOR.- "Tratado de Ginecología". 1946. Págs. 2 y siguientes.

3. HYAMS, MORTIMER N.- "Progress in Gynecology". II. Ed. 1953. Págs. 481.

4. CALATRONI, CARLOS J. y RUIZ VICENTE.- "Terapéutica Ginecológica". V. Ed. 1951. Págs. 24, 417 y siguientes.

5. PARANDELO, CARLOS A.- "Anatomía y Fisiología del Cuello Uterino en sus relaciones con la esterilidad”. Obst. y Gin. Lat. Amer. 10:324, julio 1952.

6. WOLLNER, A.- Am. Jour. Obst. Gyn., 35:10, 1936.

7. WOLLNER, A.- "Amer, Journal”, Obst. \& Gyn., 35:10, 1936.

8. SJOVALL, A.- "Acta Obst. et Gynec. Scandinav", 18:3, 1938 Suppl 4 (Cita de Rubio).

9. PAPANicolaU, G. N. TRAUt, H. F. \& MARChetTi, A. A.- "The epithelia of woman's reproductive organs", 7:29, 1948.

10. TOPKINGS, P.- Am. Jour. Obst. Gyn.", 58:654, 1949.

11. MEZZARDA, J. M.- "Factor Cervical en esterilidad", Obst. y Gin. Lat. Amer., 10:326, 1952.

12. ATKINSON y COL.- Citado por Mezzarda (op. Cit.).

13. NEUSTAEDTER, THEODORE.- "Present day knowledge of the mechanism of menstruation". The Interne, August 1946.

14. Abarbanel, A. R. Trans. Amer. Soc. for Study of Sterility, Pág. 46. 1946.

15. SMIT'H.- Citado por Abarbanel (Op. Cit.) .

16. SEGUY, J. \& SIMMONNET, J. H.- Gynec. et Obst., 18:657, 1933.

17. SEGUY, J. \& VIMEUX, J.- Gynec. et Obst., 27:346, 1933.

18. MORICARD, R. Bull Soc. d'Obst. et de Gynec., 25:426, 1936.

19. WATson, M. C.- Canad. M. A. J., Obst. \& Gyn. 32:365, 1936.

20. LAMAR, J. K. STETTLES, L. B. \& DELFS, E.- Am.: J. Physiol., 129,234, 1940 .

21. RUBIO, BORIS.- "Sinopsis Médica Internacional". Vol. II: 11, agosto 1953.

22. GUTTMACHER, A. \& SHetTles, L. B.- Human Fertility, 5.4, 1940.

23. BENNET, H. J.- Am. Jour. Obst. Gyn., 44:296, 1942.

24. POMMERENKE, W. T. \& VIERGIVER, E.- Journal Clin. Endoc., 6:99, 1946 (Citas de Rubio).

25. VIERGIVER, E. \& POMMERENKE, W. T.- Am. Jour. Obst. Gin., 54:676, 1947.

26. PALMER, R.- $10^{\circ}$ Congrés Francais de Gynéc., Lyon 1946 (cita de Campos de Paz).

27. CAMPOS DE PAZ, A.- Suppl, Vol. Am. Jour. Obst. Gyn., 61A: 790, 1951.

28. GUERRERO-ALLENDE, J.- "Estudios sobre Esterilidad", Vol. III:91. 1952 (cita de Rubio).

29. POMMERENKE, W. T.- Trans. Amer.: Gyn. Soc., 69:79, 1946. 
30. VIERGIVER, E. \& POMMERENKE, W. T. Am. Jour. Obst. Gyn., 47:231, 1944.

31. VIERGIVER, E. \& POMMERENKE, W. T. Am. Jour. Obst. Gyn., 51:192, 1946.

32. CONTRERAS, J. \& DEY, A.- "Trabajo presentado en la III. Reunión Nacional de Obstetricia y Ginecología”. Guadalajara, Jal. Sep. 1952 (cita de Rubio).

33. PAPANICOLAU, G. N.- Anat. Rec., 91:293, 1945.

34. PAPANICOLAU, G. N.- Am. Jour. Obst. Gyn., 51:316. 1946.

35. ROLAND, MAXWELL.- Am. Jour. Obst. Gyn., 63:81, 1952.

36. EORRUAT, CARLOS A.- "La Semana Médica”, marzo 25/54, 339.

37. DI PAOLA, G.- "El factor cervical en la esterilidad". Obst. y Gin. LatAmer., 10:331, julio 1952.

38. BRECKENRIDGE y COL.- Citado por Mezzarda (Op. Cit.).

39. CLIFT, BERGMAN y LUD (citados por Mezzarda) (Op. Cit.).

40. DE ALLENDE, INES \& ORIAS OSCAR.- "La Citología Vaginal Humana en condiciones normales y patológicas". E. "El Ateneo", 1947. 